\title{
Masked Palm Civet Paguma larvata Summer Diet Differs between Sexes in a Suburban Area of Central Japan
}

Author(s): Masakazu Iwama, Koji Yamazaki Miho Matsuyama, Yoshinobu Hoshino, Masumi Hisano, Chris Newman and Yayoi Kaneko

Source: Mammal Study, 42(3):185-190.

Published By: Mammal Society of Japan

https://doi.org/10.3106/041.042.0301

URL: http://www.bioone.org/doi/full/10.3106/041.042.0301

BioOne (www.bioone.org) is a nonprofit, online aggregation of core research in the biological, ecological, and environmental sciences. BioOne provides a sustainable online platform for over 170 journals and books published by nonprofit societies, associations, museums, institutions, and presses.

Your use of this PDF, the BioOne Web site, and all posted and associated content indicates your acceptance of BioOne's Terms of Use, available at www.bioone.org/page/terms of use.

Usage of BioOne content is strictly limited to personal, educational, and non-commercial use. Commercial inquiries or rights and permissions requests should be directed to the individual publisher as copyright holder. 


\title{
Masked palm civet Paguma larvata summer diet differs between sexes in a suburban area of central Japan
}

\author{
Masakazu Iwama $^{1}$, Koji Yamazaki, ${ }^{2,6}$, Miho Matsuyama ${ }^{3}$, Yoshinobu Hoshino ${ }^{3}$, Masumi Hisano ${ }^{4}$, \\ Chris Newman ${ }^{5}$ and Yayoi Kaneko ${ }^{1, *}$
}

${ }^{1}$ Carnivore Ecology and Conservation Research Group, Institute of Agriculture, Tokyo University of Agriculture and Technology, Saiwaicho 3-5-8, Fuchu, Tokyo 183-0054, Japan

${ }^{2}$ Ibaraki Nature Museum, Zoological Laboratory, 700 Osaki, Bando, Ibaraki 306-0622, Japan

${ }^{3}$ Laboratory of Vegetation Management, Institute of Agriculture, Tokyo University of Agriculture and Technology, Saiwaicho 3-5-8, Fuchu, Tokyo 183-0054, Japan

${ }^{4}$ Faculty of Natural Resources Management, Lakehead University, 955 Oliver Road, Thunder Bay, ON P7B 5E1, Canada

${ }^{5}$ Wildlife Conservation Research Unit, Department of Zoology, University of Oxford, The Recanati-Kaplan Centre, Tubney House, Abingdon Road, Tubney, Oxon OX13 5QL, UK

${ }^{6}$ Department of Forest Science, Faculty of Regional Environmental Science, Tokyo University of Agriculture, 1-1-1 Sakuragaoka, Setagaya, Tokyo 156-8502, Japan

\begin{abstract}
We studied the summer (June-August) diet of the masked palm civet (Paguma larvata) in a suburban area of Ibaraki Prefecture, using the stomach contents from road-killed carcasses. Specifically, our aim was to examine (i) monthly changes and (ii) if food habits differed between sexes, based on frequency of occurrence (FO) of the main food classes consumed. From 2009 to 2014, 61 civet carcasses were collected along the three major national highways in Ibaraki Prefecture. Civets consumed a wide range of foods such as insects, fruits, mammals, and earthworms. The FO of mammals and fruit taxa (cherries, strawberries, and persimmons) differed substantially among months, which likely reflected the peak availability of each food category/item. Females consumed amphibians, insects, and persimmons significantly more frequently than did males, likely relating to the higher food security demands of females while raising offspring. Overall, masked palm civets in Ibaraki Prefecture proved to be opportunistic and generalist feeders, eating primarily fruits and insects with a high frequency of occurrence in summer.
\end{abstract}

Key words: diet, frugivory, human-wildlife conflict, sexual size dimorphism, stomach contents.

The masked palm civet (Paguma larvata, hereafter "civet") occurs widely across South Asia, Southeast Asia, China, and Taiwan (Torii 2009); although it is now generally recognised to be an introduced species in Japan. Since the first civet was recorded in Japan (1940s) their range has expanded substantially (currently to 43 of 47 prefectures; Ministry of Agriculture, Forestry and Fisheries Japan 2008). This invasion causes a human-wildlife conflict (Woodroffe et al. 2005); civets cause considerable crop damage, amounting to 433 million yen (approximately 4.5 million US dollars) in 2012 (Ministry of Agriculture, Forestry and Fisheries Japan 2012). A better understanding of the civets' diet is therefore crucial for their effective management.
In their native range (in subtropical central China; Zhou et al. 2008), the civet diet is comprised mainly by wild/cultivated fruits and small mammals/birds; subject to dietary shifts in accord with seasonal changes in fruit availability. In Japan, the food habits of the civet have been examined in Shizuoka Prefecture (Shizuoka Prefecture 1996), Chiba Prefecture (Matsuo and Ochiai 2009), Gunma Prefecture (Anezaki et al. 2010), and in Tokyo (Yoshino and Hagiwara 2010). While these studies describe that civets rely primarily on fruits, they also highlight that civets can feed opportunistically on other foods such as arthropods, molluscs, fish, reptiles, and scavenged items.

Differences in prey preferences between the sexes have

*To whom correspondence should be addressed.E-mail: ykaneko7946@gmail.com 
been observed in various small carnivores (Boydston et al. 2001), notably mustelids (e.g., Mustela spp. Moors 1980; Birks and Dunstone 1985; Dayan et al. 1989). This has been attributed to sexual size dimorphism (Moors 1980), where either: (a) larger males tend to hunt larger prey than do smaller females (e.g., Brown and Lasiewski 1972); or (b) females need greater food security than males to raise their offspring and select home ranges to ensure sufficient food availability (e.g., Moors 1980), whereas males organise their territories not only based on food, but also to overlap breeding females, leading to them utilizing a more extensive range (Greenwood 1980; Kaneko et al. 2014; Noonan et al. 2016). Although civets are polygynandrous and sexual size dimorphism is not evident (see Ohdachi et al. 2009), male home ranges (276.8 $\pm 77.4 \mathrm{ha}$ ) in central China tend to be twice as large as those of females $(136.5 \pm 38.3 \mathrm{ha})$ (Zhou et al. 2014). This socio-spatial organisation may interact with their preferred prey selection (see also Zalewski 2007).

Our study was conducted in an area of mixed suburban housing and agricultural land in Ibaraki Prefecture Japan. Civets were first confirmed in Daigo town, in the northern part of Ibaraki Prefecture, in 1963 (Yamazaki et al. 2001) and then reached the southern part of the prefecture by the 1990s (Yoshitake 1998). Given their opportunistic feeding habits (Zhou et al. 2008), we posited that civets would consume the widest range of food items in the summer months when fruits and invertebrates are readily available (although some persimmons and oranges are also grown in the winter). Indeed, records of civets killed along a major highway in this region (Ibaraki Nature Museum, unpublished data) imply that civets are most active in the summer, with $46.7 \%$ (50 of 107) of road-killed civets recovered over just the three months (June-August between 2004 and 2013). In this first investigation of this type for this species, and focusing on this summer period, here we aimed to: (i) describe the general summer diet of the civets by analysing stomach contents, and (ii) examine differences in food habits between sexes.

\section{Materials and methods}

\section{Study area and sample collection}

This study was conducted in the northern and central parts of Ibaraki Prefecture (area ca. $437 \mathrm{~km}^{2}$ ), which lies in the north-eastern part of the Kanto Plain (Fig. 1). The mean human population density over this prefecture was $476.8 / \mathrm{km}^{2}$ in 2016 (according to the Ibaraki Prefectural Government 2016). This landscape comprised a mosaic

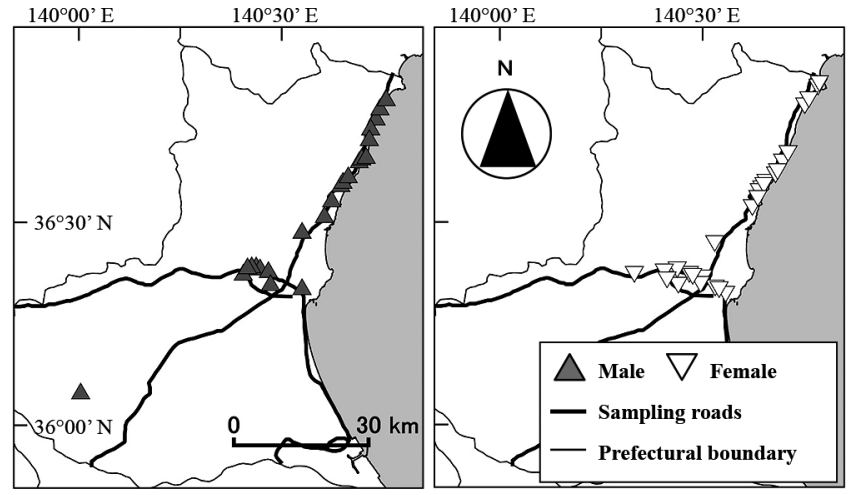

Fig. 1. Locations from which masked palm civet carcasses were collected in Ibaraki Prefecture.

of small areas of farmland (58.4\%), forest (19.2\%), urban development $(18.0 \%)$, wetland $(1.9 \%)$, orchard $(1.3 \%)$, and other habitat (1.2\%), as well as two medium-sized cities (Mito and Hitachi-with an averaged population density of 1036.6/km², January 2009; Hitachi City 2010; Mito City 2010). Forests mainly consisted of plantations of Japanese cedar (Cryptomeria japonica), Japanese cypress (Chamaecyparis obtusa), Japanese red pine (Pinus densiflora), sawtooth oak (Quercus acutissima), and konara oak $(Q$. serrata). Japanese pears (Pyrus pyrifolia var. culta), Japanese chestnuts (Castanea crenata), Japanese apricots (Armeniaca mume), persimmons (Diospyros kaki), and grapes (Vitaceae spp.) were widely cultivated in orchards.

Between 2009 and 2014, we collected 118 civet road kills from the three major national highways transecting Ibaraki Prefecture (Routes 6, 50, and 51, with a total length of ca. $323 \mathrm{~km}$; Fig. 1). Sixty-one of these casualties occurred in summer (June-August), 28 in spring (MarchMay), and 23 in autumn (September-November); only six were recovered in winter (December-February), which was insufficient to support statistical analysis. From these, we collected stomach contents samples from those civets killed during the summer, to coincide with the ripening season of vulnerable crops. Carcasses were stored (at $-25^{\circ} \mathrm{C}$ to $-30^{\circ} \mathrm{C}$ ) at the Ibaraki Nature Museum prior to necropsy and the dissection of stomach contents. Stomach content samples were then either preserved in $80 \%$ ethanol $(2009-2013)$ or frozen $\left(-15^{\circ} \mathrm{C} ; 2014\right)$ until dietary analysis. All 61 carcasses (29 males and 32 females) were adult, where maturity was determining by head-body length exceeding $440 \mathrm{~mm}$, following Torii (2009), who determined that, in the Shizuoka population, civets over $469 \mathrm{~mm}$ were $>2$ years old. 


\section{Dietary analysis}

Stomach content examination was performed following the methods of Matsuo and Ochiai (2009), and referring to Fukue et al. (2011). Stomach contents were washed through a $0.5-\mathrm{mm}$-mesh sieve with $1 \mathrm{~L}$ water. Food items were classified into 14 categories (that is, these 'items' comprised 'categories'): 'mammals', 'birds', 'reptiles', 'amphibians', 'fish', 'insects', 'crustaceans (crabs and shrimps)', 'molluscs (slugs and snails)', 'earthworms', 'other animals (e.g., centipedes or spiders)', 'unidentified animals', 'berries and seeds', 'other plants (i.e., grasses, twigs, plant galls)', 'artificial materials (i.e., humansubsidised food, garbage, plastic, vinyl)', along with incidental items such as own hairs, inorganic materials, and unidentified items, which were excluded from the analysis. We identified seeds present up to the species level. We also examined the residual water used for washing stomach contents, to count any earthworm chaetae present, using a microscope $(\times 40)$, based on the methods of Kruuk (1989), Yamamoto (1994), and Kaneko et al. (2009).

The frequency of occurrence $(\%, F O)$ of each food item was calculated as: the number of occurrences of each food item/the total number of stomach items $\times 100$. We also recorded the number of occurrences of seeds from each plant genus represented. We used Fisher's exact test for independence to test for any differences in consumed food categories and fruit items over the three summer months, and to test for differences between the sexes. If a significant $(\alpha=0.05)$ monthly difference was detected, we then conducted post-hoc pairwise Fisher's exact tests with Bonferroni correction to determine in which month civets consumed these items most frequently (Tsuji et al. 2014; Hisano et al. 2017). For the Bonferroni post-hoc test, the statistical significance standard $(\alpha)$ was adjusted to 0.017 (i.e., $0.05 / 3$ months). All statistical analyses were conducted using R 3.2.4 (R Development Core Team 2016).

\section{Results}

\section{General summer diet}

Across all five years, on average individual civets consumed foods from $4.26 \pm 1.16$ categories (range 1-7), excluding unidentified food. Insects had the highest frequency of occurrence $(90.2 \%)$, followed by berries and seeds $(88.5 \%)$ and other plants (85.2\%). Earthworms occurred in $45.9 \%$ of samples and molluscs in $52.5 \%$ (Table 1). Vertebrate categories were eaten far less frequently; $1.2 \%$ for mammals and $14.8 \%$ for birds. Artificial materials, represented by small pieces of vinyl, were found in only three stomach samples. Only the mammal category differed significantly with month (Fisher's exact test for independence, $P=0.018$ ); being consumed sig-

Table 1. The frequency of occurrence (FO) and the number of the food categories that occurred in masked palm civet stomachs in Ibaraki Prefecture between 2009 and 2014

\begin{tabular}{|c|c|c|c|c|c|c|c|c|c|c|c|c|}
\hline \multirow{3}{*}{ Food category } & \multicolumn{4}{|c|}{ Sex (all months) } & \multicolumn{6}{|c|}{ Month (both sexes) } & \multirow{2}{*}{\multicolumn{2}{|c|}{ Total $(n=61)$}} \\
\hline & \multicolumn{2}{|c|}{ Male $(n=29)$} & \multicolumn{2}{|c|}{ Female $(n=32)$} & \multicolumn{2}{|c|}{ June $(n=24)$} & \multicolumn{2}{|c|}{ July $(n=14)$} & \multicolumn{2}{|c|}{ August $(n=23)$} & & \\
\hline & $n$ & $\mathrm{FO}(\%)$ & $n$ & $\mathrm{FO}(\%)$ & $n$ & FO $(\%)$ & $n$ & FO $(\%)$ & $n$ & FO $(\%)$ & $n$ & $\mathrm{FO}(\%)$ \\
\hline \multicolumn{13}{|l|}{ Animal matter } \\
\hline Mammals & 9 & 31.0 & 4 & 12.5 & 9 & 37.5 & 0 & 0.0 & 4 & 17.4 & 13 & 21.3 \\
\hline Birds & 7 & 24.1 & 2 & 6.3 & 5 & 20.8 & 2 & 14.3 & 2 & 8.7 & 9 & 14.8 \\
\hline Reptiles & 1 & 3.4 & 1 & 3.1 & 2 & 8.3 & 0 & 0.0 & 0 & 0.0 & 2 & 3.3 \\
\hline Amphibians & 0 & 0.0 & 6 & 18.8 & 2 & 8.3 & 2 & 14.3 & 2 & 8.7 & 6 & 9.8 \\
\hline Fish & 1 & 3.4 & 1 & 3.1 & 1 & 4.2 & 1 & 7.1 & 0 & 0.0 & 2 & 3.3 \\
\hline Insects & 23 & 79.3 & 32 & 100.0 & 21 & 87.5 & 13 & 92.9 & 21 & 91.3 & 55 & 90.2 \\
\hline Molluscs & 15 & 51.7 & 17 & 53.1 & 14 & 58.3 & 9 & 64.3 & 9 & 39.1 & 32 & 52.5 \\
\hline Earthworms & 13 & 44.8 & 15 & 46.9 & 15 & 62.5 & 6 & 42.9 & 7 & 30.4 & 28 & 45.9 \\
\hline Other animals & 2 & 6.9 & 2 & 6.3 & 1 & 4.2 & 2 & 14.3 & 1 & 4.3 & 4 & 6.6 \\
\hline Unidentified animals & 6 & 20.7 & 9 & 28.1 & 5 & 20.8 & 2 & 14.3 & 8 & 34.8 & 15 & 24.6 \\
\hline \multicolumn{13}{|l|}{ Plant matter } \\
\hline Berries and seeds & 25 & 86.2 & 29 & 90.6 & 20 & 83.3 & 11 & 78.6 & 23 & 100.0 & 54 & 88.5 \\
\hline Other plants & 25 & 86.2 & 27 & 84.4 & 20 & 83.3 & 10 & 71.4 & 22 & 95.7 & 52 & 85.2 \\
\hline Artificial materials & 0 & 0.0 & 3 & 9.4 & 1 & 4.2 & 0 & 0.0 & 2 & 8.7 & 3 & 4.9 \\
\hline
\end{tabular}


Table 2. The number of fruits that occurred in the stomach contents of masked palm civets in Ibaraki Prefecture between 2009 and 2014

\begin{tabular}{|c|c|c|c|c|c|}
\hline \multirow[b]{2}{*}{ Fruit taxon } & \multicolumn{2}{|c|}{ Sex (all months) } & \multicolumn{3}{|c|}{ Month (both sexes) } \\
\hline & $\begin{array}{c}\text { Male } \\
(n=29)\end{array}$ & $\begin{array}{l}\text { Female } \\
(n=32)\end{array}$ & $\begin{array}{c}\text { June } \\
(n=24)\end{array}$ & $\begin{array}{c}\text { July } \\
(n=14)\end{array}$ & $\begin{array}{l}\text { August } \\
(n=23)\end{array}$ \\
\hline \multicolumn{6}{|l|}{ Rosaceae } \\
\hline Cerasus spp. & 8 & 8 & 13 & 1 & 0 \\
\hline Fragaria spp. & 5 & 5 & 8 & 1 & 0 \\
\hline Armeniaca spp. & 3 & 4 & 1 & 2 & 1 \\
\hline Rubus spp. & 3 & 4 & 1 & 1 & 1 \\
\hline Chaenomeles speciosa & 0 & 0 & 0 & 1 & 0 \\
\hline \multicolumn{6}{|l|}{ Ebenaceae } \\
\hline Diospyros kaki & 4 & 12 & 0 & 0 & 8 \\
\hline \multicolumn{6}{|l|}{ Lauraceae } \\
\hline Machilus thunbergi & 0 & 2 & 0 & 2 & 2 \\
\hline Lauraceae spp. & 1 & 1 & 0 & 2 & 0 \\
\hline \multicolumn{6}{|l|}{ Cannabaceae } \\
\hline Celtis sinensis & 3 & 9 & 0 & 0 & 6 \\
\hline \multicolumn{6}{|l|}{ Theaceae } \\
\hline Camellia japonica & 4 & 4 & 3 & 2 & 0 \\
\hline \multicolumn{6}{|l|}{ Elaeagnaceae } \\
\hline Elaeagnus multiflora & 3 & 3 & 2 & 1 & 0 \\
\hline Elaeagnus spp. & 1 & 1 & 2 & 0 & 0 \\
\hline \multicolumn{6}{|l|}{ Moraceae } \\
\hline Morus australis & 1 & 1 & 2 & 2 & 0 \\
\hline \multicolumn{6}{|l|}{ Celastraceae } \\
\hline Euonymus spp. & 0 & 0 & 0 & 2 & 0 \\
\hline Celastrus orbiculatus & 1 & 1 & 1 & 0 & 0 \\
\hline \multicolumn{6}{|l|}{ Phytolaccaceae } \\
\hline Phytolacca americana & 1 & 2 & 0 & 0 & 1 \\
\hline \multicolumn{6}{|l|}{ Vitaceae } \\
\hline Vitis sp. & 1 & 2 & 0 & 0 & 1 \\
\hline \multicolumn{6}{|l|}{ Helwirgiaceae } \\
\hline Helwingia japonica & 0 & 0 & 0 & 1 & 0 \\
\hline \multicolumn{6}{|l|}{ Solanaceae } \\
\hline Solanum sp. & 1 & 2 & 0 & 0 & 1 \\
\hline \multicolumn{6}{|l|}{ Polygonaceae } \\
\hline Polygonaceae sp. & 0 & 0 & 0 & 1 & 0 \\
\hline \multicolumn{6}{|l|}{ Lardizabalaceae } \\
\hline Lardizabalaceae sp. & 1 & 1 & 1 & 0 & 0 \\
\hline
\end{tabular}

nificantly more frequently in June than in July (Post-hoc pairwise Fisher's exact tests, $P=0.014$ ).

Focusing on fruit consumption, civets ate seeds from 14 plant families (Table 2). Among these, the most frequently observed family was Rosaseae $(n=23$, predominantly Cerasus spp. $n=14)$, followed by Ebenaceae $(n=$ $8)$, Lauraceae $(n=6)$, and Cannabaceae $(n=6)$ across the three summer months (Table 2). There were significant monthly differences in FOs of Cerasus spp. [cherries] (Fisher's exact test for independence, $P<0.001$ ) and Fragaria spp. [strawberries] $(P=0.002)$; specifically, civets consumed Cerasus spp. significantly more frequently in June $(n=13)$ [versus July $(n=1$, post-hoc pairwise Fisher's exact tests, $P<0.001$ ) and August ( $n=$ 0, $P<0.001)]$; similarly Fragaria spp. were consumed significantly most frequently in June $(n=8)$ [versus August $(n=0, P=0.004)$ although there was no significant difference between June and July $(n=1, P=0.115)]$. In contrast, $D$. kaki [persimmon] was eaten exclusively in August $(n=8)$, and not at all in other months $(n=0$, Fisher's exact test for independence, $P<0.001$ ).

\section{Comparison of diet between sexes}

Overall, there was no significant sex-related difference in the FO of mammals, reptiles, fish, molluscs, earthworms, berries, and seeds (Fisher's exact test for independence, $P>0.05$ ). However, females consumed amphibians (FO: $18.8 \%, P=0.025)$ and insects (FO: $100 \%, P=0.009$ ) more frequently than did males (FO: $0.0 \%$ for both categories; Table 1 ). With regards to fruit species, only $D$. kaki consumption differed between the sexes, being eaten more frequently by females $(n=8)$ than by males $(n=0$, Fisher's exact test for independence, $P=0.045$; Table 2).

\section{Discussion}

Civets proved to be versatile and adaptable generalist omnivores in our study region, with individual stomachs typically including food types from 4.26 categories. Generally, this corroborates previous studies in Japan (Torii 1986, 1993; Shizuoka Prefecture 1996; Matsuo and Ochiai 2009). Nevertheless, there were some differences. For instance, although we found that, during the summer, insects occurred most frequently in the diet, followed by fruits, snails and slugs, in accord with the report from Chiba Prefecture (Matsuo and Ochiai 2009), we found a higher FO of mammals, birds, molluscs, earthworms, and fruits than they did. We also found no crustaceans (crabs and shrimps) versus an FO of 5.6\% in the Chiba Prefecture study. Furthermore, although we found similar food items to those eaten in the civets' native range in China (Zhou et al. 2008), invertebrates such as insects, snails, and slugs occurred in higher proportions in our study; whereas we found a lower FO of mammal consumption than in the civet's native Chinese range. Note, however, that diets in this central China study were expressed as 
dry biomass, which generally produces a narrow over- or under-estimate of the proportion of food items compared to FO methods (e.g., Klare et al. 2011).

\section{Monthly changes in consumption of fruits}

Fruits were one of the most important food categories eaten by civets in our study. As in Shizuoka Prefecture (1996), we found that civets favoured sweet fruits such as Rosaceae spp. (e.g., cherry, strawberry) and D. kaki (persimmon), and FOs of these primary fruit taxa showed significant monthly changes. The intensive consumption of Cerasus spp. and Fragaria spp. in June appeared to be associated with the peak availability of these fruits as they ripened in early-summer (Oda 1991; Mogi et al. 2000). Similarly, that $D$. kaki was only eaten in late-summer (August) coincides with the beginning of its ripening season, into autumn, (October-November; Yamada et al. 1994). Therefore civets in our study region appeared to be feeding opportunistically, and we speculate that they were shifting the composition of the main fruit species they consumed in proportion to changes in the environmental availability of these fruits.

\section{Differences in diet between the sexes}

Female civets ate amphibians and insects significantly more frequently than did males, likely as an easily acquired source of protein needed for rearing offspring. According to Zhou et al. (2014), the average 95\% minimum convex polygon home range size of male civets was twice that of females in Central China. Many Viverridae species are solitary (Sotani and Ito 1991). Nevertheless masked palm civets can form maternal-offspring groups that include offspring up to one year old (Torii 2009; Zhou et al. 2014). While suckling cubs, females are limited in the distances they can move, and the time for which they can safely leave litters unattended. Masked palm civet can breed throughout the year, although breeding occurs mostly between spring and autumn. Subsequently, the cub-rearing period lasts approximately two months (Shizuoka Prefecture 1996), which aligns with our study period. As a consequence, maternal females have less opportunity to hunt for prey able to evade capture, such as mammals and birds, and may more easily acquire amphibians and insects as a vital source of protein (see also Zalewski 2007).

To conclude, masked palm civets in Ibaraki Prefecture were generalist feeders in our study, eating fruits and insects with a high frequency of occurrence in the summer. They consumed a variety of fruits from both wild and cultivated trees. Our data also demonstrate that their food habits differed between males and females, likely relating to the higher food security demands of females while raising offspring (see Sandell 1989).

Acknowledgments: We thank Kazuo Obata, Takeshi Fujii, Tsuyoshi Ishizuka, Suzunui Construction Co. Ltd., and Showa Kensetsu Co. Ltd. for their help with sample collection. This work was supported in part by Grants-inAid for Scientific Research (No. 26257404) from the Japan Society for the Promotion of Science, Japan.

\section{References}

Anezaki, T., Sakaniwa, H. and Tanaka, Y. 2010. Spatial distribution and diet of palm civet (Paguma larvata) in Gunma Prefecture. Bulletin of Gunma Museum of Natural History 14: 99-102 (in Japanese).

Birks, J. D. S. and Dunstone, N. 1985. Sex-related differences in the diet of the mink Mustela vison. Ecography 8: 245-252.

Boydston, E. E., Morelli, T. L. and Holekamp, K. E. 2001. Sex differences in territorial behavior exhibited by the spotted hyena (Hyaenidae, Crocuta crocuta). Ethology 107: 369-385.

Brown, J. H. and Lasiewski, R. C. 1972. Metabolism of weasels: the cost of being long and thin. Ecology 53: 939-943.

Dayan, T., Simberloff, D., Tchernov, E. and Yom-Tov, Y. 1989. Interand intraspecific character displacement in mustelids. Ecology 70 : $1526-1539$.

Fukue, Y., Takeshita, T. and Nakanishi, N. 2011. Diet analysis methods to assess the food habits of carnivore in Japan I. Canidae, Mustelidae and Felidae. Mammalian Science 51: 129-142 (in Japanese).

Greenwood, P. J. 1980. Mating systems, philopatry and dispersal in birds and mammals. Animal Behaviour 28: 1140-1162.

Hisano, M., Hoshino, L., Kamada, S., Masuda, R., Newman, C. and Kaneko, Y. A. 2017. Comparison of visual and genetic techniques for identifying Japanese marten scats-enabling diet examination in relation to seasonal food availability in a sub-alpine area of Japan. Zoological Science 34: 137-146.

Hitachi City. 2010. Population and the Number of Households in Hitachi City. Available at http://www.city.hitachi.lg.jp/shisei/008/ 001/p003151_d/fil/00001_20110111_0005.xls (Accessed 3 May 2017) (in Japanese).

Ibaraki Prefectural Government. 2016. Population and the Number of Households in Ibaraki Prefecture. Available at https://www.pref. ibaraki.jp/kikaku/tokei/fukyu/tokei/betsu/jinko/getsu/jinko1601s. html (Accessed 3 May 2017) (in Japanese).

Kaneko, Y., Kanda, E., Tashima, S., Masuda, R., Newman, C. and Macdonald, D. W. 2014. The socio-spatial dynamics of the Japanese badger (Meles anakuma). Journal of Mammalogy 95: 290-300.

Kaneko, Y., Shibuya, M., Yamaguchi, N., Fujii, T., Okumura, T., Matsubayashi, K. and Hioki, Y. 2009. Diet of Japanese weasels (Mustela itatsi) in a sub-urban landscape: implications for yearround persistence of local populations. Mammal Study 34: $97-106$.

Klare, U., Kamler, J. F. and Macdonald, D. W. 2011. A comparison and critique of different scat-analysis methods for determining carnivore diet. Mammal Review 41: 294-312.

Kruuk, H. 1989. The Social Badger: Ecology and Behaviour of a Group-Living Carnivore (Meles meles). Oxford University Press, 
Oxford, $180 \mathrm{pp}$.

Matsuo, R. and Ochiai, K. 2009. Dietary overlap among two introduced and one native sympatric carnivore species, the raccoon, the masked palm civet, and the raccoon dog, in Chiba Prefecture, Japan. Mammal Study 34: 187-194.

Ministry of Agriculture, Forestry and Fisheries Japan. 2008. The Manual of the Prevention of Damage by Wild Animals and Birds - the Masked Palm Civet. Available at http://www.maff.go.jp/j/ seisan/tyozyu/higai/h_manual/h20_03b/pdf/data0.pdf (Accessed 20 December 2014) (in Japanese).

Ministry of Agriculture, Forestry and Fisheries Japan. 2012. The Transition of Crop Damages by Wild Animals and Birds. Available at http://www.maff.go.jp/j/seisan/tyozyu/higai/h_manual/h20_03b/ pdf/data0.pdf (Accessed 20 December 2014) (in Japanese).

Mito City. 2010. Investigation of Population per Age. Available at http://www.city.mito.lg.jp/001544/001567/001815/p008928_d/ fil/011.xls (Accessed 3 May 2017) (in Japanese).

Mogi, T., Takahashi, H., Katsuyama, T., Ishii, H., Ohta, K., Shirokawa, S., Sakio, H., Nakagawa, T. and Yoshiyama, H. 2000. Woody Plants of Japan: Choripetalae I. Yama-Kei Publishers, Tokyo, 719 pp. (in Japanese).

Moors, P. J. 1980. Sexual dimorphism in the body size of mustelids (Carnivora): the roles of food habits and breeding systems. Oikos 34: $147-158$.

Noonan, M. J., Johnson, P. J., Kitchener, A. C., Harrington, L. A., Newman, C. and Macdonald, D. W. 2016. Sexual size dimorphism in musteloids: An anomalous allometric pattern is explained by feeding ecology. Ecology and Evolution 6: 8495-8501.

Oda, Y. 1991. The strawberry in Japan. In (Dale, A. and Luby, J. J., eds.) The Strawberry into the 21 st Century, pp. 36-46. Timber Press, Portland.

Ohdachi, S. D., Ishibashi Y., Iwasa, M. A. and Saitoh, T. 2009. The Wild Mammals of Japan. Shoukadoh, Kyoto, 506 pp.

R Development Core Team 2016. R: A Language and Environment for Statistical Computing. R Foundation for Statistical Computing, Vienna, Austria. Available at https://www.r-project.org/ (Accessed 30 October 2016).

Sandell, M. 1989. The mating tactics and spacing patterns of solitary carnivores. In (Gittleman, J. L., ed.) Carnivore Behavior, Ecology, and Evolution, pp. 164-182. Chapman and Hall, London.

Shizuoka Prefecture. 1996. The Investigation Report of the Masked Palm Civets in Shizuoka Prefecture. Shizuoka Prefecture, Shizuoka, 52 pp. (in Japanese).

Sotani, K. and Ito, K. 1991. Classification of Viverridae. In (Imaizumi, Y., ed.) Carnivora (Mammals in the World-Classification and Breeding II), pp. 78-118. Tokyo Zoological Park Society, Tokyo (in Japanese).

Torii, H. 1986. Food habits of the masked palm civet, Paguma larvata Hamilton-Smith. Journal of the Mammalogical Society of Japan
11: 39-43.

Torii, H. 1993. Food habits of the masked palm civet (I) contents analysis of the faeces collected in Hamakita. Bulletin of the Shizuoka Prefecture Forestry Technology Center 21: 9-15 (in Japanese).

Torii, H. 2009. Paguma larvata (Smith, 1827). In (Ohdachi, S. D., Ishibashi, Y., Iwasa, M. A. and Saitoh, T., eds.) The Wild Mammals of Japan, pp. 267-268. Shoukadoh, Kyoto.

Tsuji, Y., Yasumoto, Y. and Takatsuki, S. 2014. Multi-annual variation in the diet composition and frugivory of the Japanese marten (Martes melampus) in western Tokyo, central Japan. Acta Theriologica 59: 479-483.

Woodroffe, R., Thirgood, S. and Rabinowitz, A. 2005. The impact of human-wildlife conflict on natural systems. In (Woodroffe, R., Thirgood, S. and Rabinowitz, A., eds.) People and Wildlife, Conflict or Co-existence?, pp. 1-12. Cambridge University Press, Cambridge.

Yamada, M., Yamane, H., Sato, A., Hirakawa, N. and Wang, R. 1994. Variations in fruit ripening time, fruit weight and soluble solids content of oriental persimmon cultivars native to Japan. Journal of the Japanese Society for Horticultural Science 63: 485-491.

Yamamoto, Y. 1994. Comparative analyses on food habits of Japanese marten, red fox, badger and raccoon dog in Mt. Nyukasa, Nagano Prefecture, Japan. Natural Environmental Science Research 7: 45-52 (in Japanese).

Yamazaki, K., Koyanagi, K. and Tsuji, A. 2001. List of mammals found in Ibaraki Prefecture, central part of Japan. Bulletin of Ibaraki Nature Museum 4: 103-108 (in Japanese).

Yoshino, I. and Hagiwara, S. 2010. Record of Nyctereutes procyonoides and Paguma larvata by sensor photography and fecal analysis in the Institute for Nature Study. Miscellaneous Reports of the Institute for Nature Study 41: 79-83 (in Japanese).

Yoshitake, W. 1998. Miscellaneous notes of animals in Ibaraki Prefecture: requiem for road killed animals. Ibaraki Seibutsu 18: 33-57 (in Japanese).

Zalewski, A. 2007. Does size dimorphism reduce competition between sexes? The diet of male and female pine martens at local and wider geographical scales. Acta Theriologica 52: 237-250.

Zhou, Y., Newman, C., Palomares, F., Zhang, S., Xie, Z. and Macdonald, D. W. 2014. Spatial organization and activity patterns of the masked palm civet (Paguma larvata) in central-south China. Journal of Mammalogy 95: 534-542.

Zhou, Y., Zhang, J., Slade, E., Zhang, L., Palomares, F., Chen, L., Wang, X. and Zhang, S. 2008. Dietary shifts in relation to fruit availability among masked palm civets (Paguma larvata) in central China. Journal of Mammalogy 89: 435-447.

Received 23 March 2017. Accepted 9 June 2017. Editor was Yuya Watari. 